\title{
Encapsulation of Azaphosphatranes and Proazaphosphatranes in Confined Spaces
}

Jean-Pierre Dutasta*[b] and Alexandre Martinez ${ }^{*[a]}$

\section{Azaphosphatranes and Proazaphosphatranes in Confined Spaces}

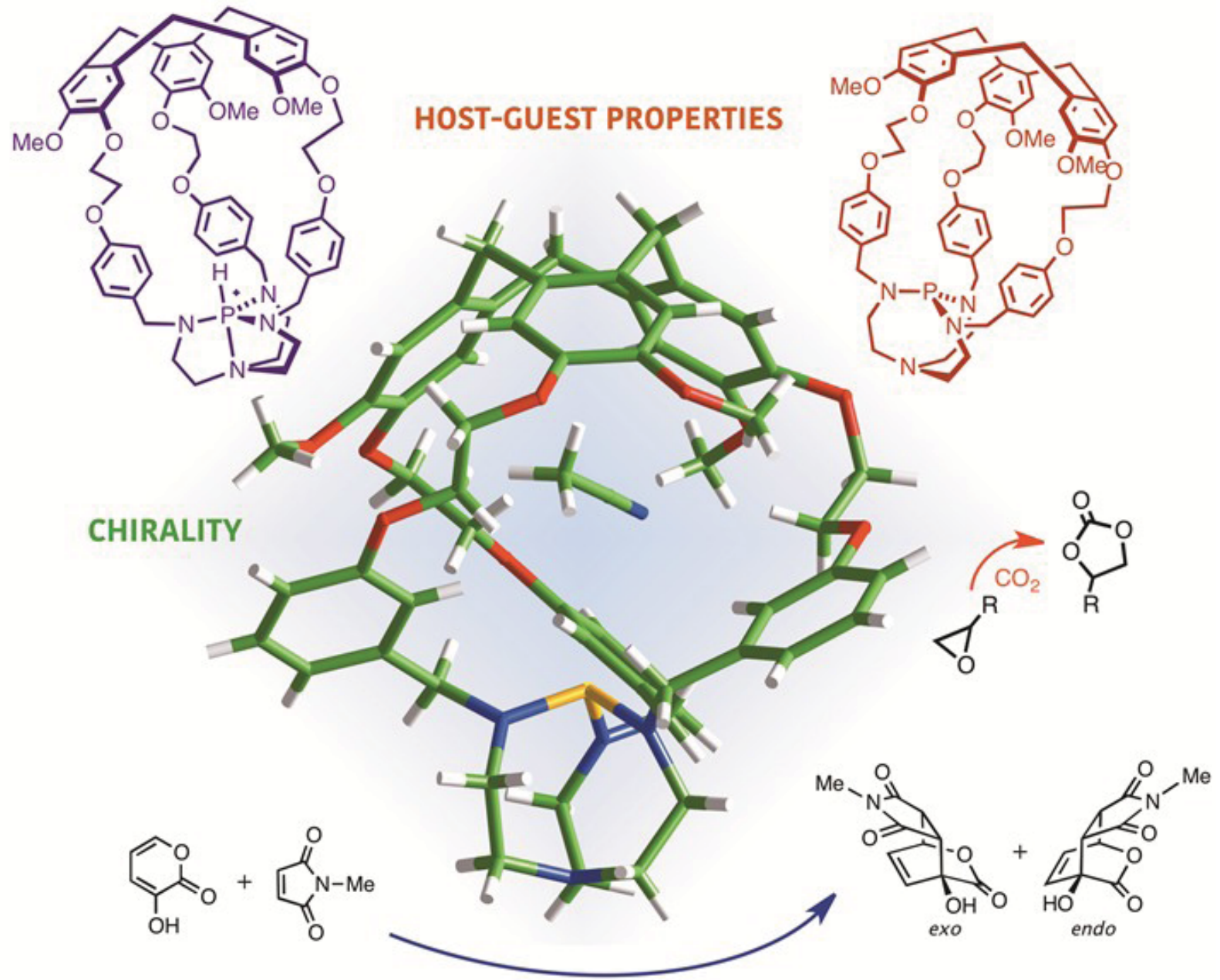

CATALYTIC PERFORMANCE 
Proazaphosphatranes (also named Verkade's superbases) and their azaphosphatrane conjugated acids have been recently been shown to be confined in either covalent or self-assembled molecular cages, or immobilized in nanopores of hybrid materials. The encapsulation of these phosphorus moieties turns out to strongly affect both their acid-base, catalytic, and recognition properties. The thermodynamics and kinetics of the proton transfer as well as the selectivity and catalytic activities

\section{Introduction}

Proazaphosphatranes P@1, also named Verkade's superbases, and azaphosphatranes $\mathbf{P H}^{+} @ 1$ (Scheme 1), were first synthesized in 1989 by J. G. Verkade. ${ }^{[1]}$ The basicity of proazaphosphatranes was estimated by Schwesinger and Verkade and a $\mathrm{p} K_{\mathrm{a}}$ of 32 was measured for this class of compounds. ${ }^{[2]}$ The protonation of proazaphosphatranes takes place on the phosphorus atom, in sharp contrast with phosphazene bases (Schwesinger's bases), which are protonated on the nitrogen atom. The resulting weakly acidic azaphosphatranes are highly stable because of the formation of the azatrane structure that includes three five-membered rings and allows for the delocalization of the positive charge on the five heteroelements. The thermodynamic stability of this cation accounts for the high basicity of the conjugated Verkade's superbase.

Proazaphosphatranes proved to be remarkably nucleophilic and basic organocatalysts in numerous reactions where yields and selectivity are often higher than with other systems. Reactions can be run under mild conditions and side reactions are strongly limited when proazaphosphatranes are used as catalysts..$^{[3,4]}$

Beside their use as organocatalysts, other aspects of the chemistry of proazaphosphatranes have been also reported. They were found to be original ligands for transition metals. For instance, J. G. Verkade reported Hartwig-Buchwald reactions or Suzuki coupling, involving proazaphosphatranes as ligands for palladium. ${ }^{[5]}$ The stereoelectronic properties of these ligands were investigated in detail by Yang et al.. In particular, they synthesized nickel-proazaphosphatrane complexes and described carefully their structures and spectroscopic properties. ${ }^{[6]}$ Alongside these studies, our group reported the synthesis of Verkade's superbase-gold complexes and compared the properties of proazaphosphatranes when used as ligand for gold(I) with those of phosphines and carbenes. ${ }^{[7]}$ Furthermore, Kremp-

[a] Prof. A. Martinez

Aix Marseille Univ, CNRS

Centrale Marseille, iSm2, Marseille (France)

E-mail: alexandre.martinez@centrale-marseille.fr

[b] Dr. J.-P. Dutasta

Laboratoire de Chimie, École Normale Supérieure de Lyon

CNRS, UCLB

46 allée d'Italie, F-69364 Lyon France

E-mail: jean-pierre.dutasta@ens-lyon.fr of Verkade's superbases were strongly changed upon their confinement in a hemicryptophane cavity. Moreover, selfassembled cages, including azaphosphatrane moieties, were found to display remarkable anion recognition properties in water. In this Minireview, these new aspects of the chemistry of aza- and proaza-phosphatranes are presented, in order to highlight the great potential of such an approach

ner et al. developed an elegant application of proazaphosphatranes: they demonstrated that, when associated to a moderate Lewis acid, they form "inverse frustrated Lewis acid/base" systems, capable of $\mathrm{H}_{2}$ activation, leading to an efficient catalytic system for hydrogenation under metal free conditions. $^{[8,9]}$

If the chemistry of proazaphosphatranes has arouse a great interest and is still a dynamic field of research with the recent and original developments described above, their weak acid azaphosphtatrane counterparts have received little attention. J. G. Verkade showed that, when grafted on Merrifield polymer resin, they can act as efficient catalysts for the Strecker reaction. ${ }^{[10]}$ Later, we demonstrated that they are also robust phase transfer catalysts, ${ }^{[1]]}$ and more recently, that they display remarkable catalytic activities for the conversion of $\mathrm{CO}_{2}$ and epoxides into cyclic carbonates. ${ }^{[12]}$

During the last decade, new advances in the chemistry of proazaphosphatranes and azaphosphatranes focused on the design and behavior of these species in confined spaces like that found in the inner cavities of molecular containers or metal-organic frameworks (MOF). Indeed, the reactivity and efficiency of encaged catalysts are often strongly enhanced when introduced in such structures. These encaged species can also lead to efficient host molecules for the recognition of various substrates and form original host-guest systems.

Examples of cage compounds with endohedral proazaphosphatrane or azaphosphatrane moieties are quite rare in the literature. However, these functional groups have been efficiently grafted in the molecular cavity of hemicryptophane host molecules or encapsulated in MOF structures. Hemicryptophanes, which combines a cyclotriveratrylene (CTV) unit with another $C_{3}$ symmetrical moiety, ${ }^{[13]}$ have been chosen as the class of covalent cage molecules to encapsulate azaphosphatranes and proazaphosphatranes because: (i) both these moieties and the CTV unit display a $C_{3}$ symmetry, allowing for a simple synthesis and analysis of the target molecules, ${ }^{[14]}$ (ii) hemicryptophanes exhibit remarkable recognition properties, ${ }^{[15]}$ and

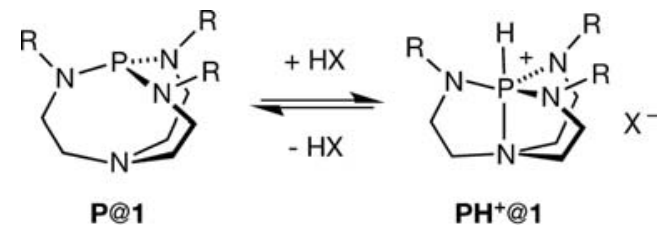

Scheme 1. Structures of proazaphosphatranes $\mathbf{P} @ 1$ and azaphosphatranes $\mathrm{PH}^{+} @ 1$ ( $\mathrm{R}=$ alkyl or benzyl groups). 
(iii) when catalytic sites are confined in the cavity of hemicryptophanes, an improvement of the catalytic activity, the selectivity or the stability of catalyst has been observed. ${ }^{[16]}$ Interestingly, azaphosphatranes have also been grafted into mesoporous silica to produce efficient solid catalysts. This minireview provides an overview of current progress in the design of encaged proazaphosphatranes or azaphosphatranes. The consequences on their properties are also discussed

\section{Proazaphosphatranes (Verkade's superbases) in Confined Spaces}

\section{Basicity}

In 2011, the synthesis of the first Verkade's superbase encapsulated in a covalent cage was achieved. The hemicryptophane ligand $2 \mathrm{a}$ was added to a solution of $\left[\left(\mathrm{CH}_{3}\right)_{2} \mathrm{~N}\right]_{2} \mathrm{PCl}$ in $\mathrm{CH}_{3} \mathrm{CN}$ leading to the expected $\mathbf{P H}^{+} @ 2 \mathrm{a}$ in $35 \%$ yield; the subsequent deprotonation with potassium t-butoxide as a base afforded the confined superbase $\mathbf{P} @ \mathbf{2} \mathbf{a}$ in $80 \%$ yield (Scheme 2). ${ }^{[17]}$ The model superbase $\mathbf{P} @ 3 \mathrm{a}$, which lacks a cavity, was also prepared in order to investigate the effect of the confinement on the reactivity and basicity of the proazaphosphatranes. The $\mathrm{p} K_{\mathrm{a}}$ of P@2 $\mathrm{a}$ and $\mathbf{P} @ 3$ a were estimated from ${ }^{1} \mathrm{H}$ and ${ }^{31} \mathrm{P}$ NMR experiments to give $K_{\mathrm{a}}$ values of $1.03 \times 10^{-33}$ and $7.25 \times 10^{-33}$ for $\mathbf{P} @ 2 \mathrm{a}$ and $\mathbf{P} @ \mathbf{3} \mathbf{a}$, respectively, showing that the confined proazaphosphatrane $\mathbf{P} @ \mathbf{2} \mathbf{a}$ is seven times more basic than its model counterpart $\mathbf{P} @ 3 \mathbf{a}$. Moreover, the kinetic of the proton transfer was also investigated: although the encaged Verkade's superbase $\mathbf{P} @ \mathbf{2} \mathbf{a}$ is thermodynamically more basic than the model $\mathbf{P} @ 3 \mathbf{a}$, its protonation rate constant is more than one hundred times slower. This highlights that the confinement induces strongly opposite effects on the thermodynamics and kinetics of the proton transfer.
As shown in Figure 1, Verkade's superbases were encapsulated in cavities presenting different shape and volume, and their model parents were also prepared for comparison. ${ }^{[18]}$ Upon confinement, a drop in basicity was observed for P@2 b which is 30 times less basic than its model parent $\mathbf{P} @ \mathbf{3} \mathbf{b}$, whereas the basicity of $\mathbf{P} @ \mathbf{2} \mathbf{c}$ is two order of magnitude higher than that of its model $\mathbf{P} @ 3 \mathbf{c}$. The X-ray crystal structures show that $\mathbf{P H}^{+} @ 2 \mathrm{c}$ benefits from additional cation- $\pi$ interactions between the aromatic moieties of the linkers and the acidic proton of the azaphosphatrane unit. This stabilization of the weak azaphosphatrane conjugated acid can account for the improvement of the basicity observed. Furthermore, a strong decrease of the rate of protonation was also observed for these compounds in agreement with the restricted accessibility to the basic phosphorus center. In line with these studies, Makita et al. reported the synthesis of the encaged azaphosphatranes $\mathrm{PH}^{+}$ @2 $\mathbf{d}$ (Scheme 3). ${ }^{[19]}$ Despite numerous attempts, they were not able to remove the acidic proton and to isolate the corresponding proazaphosphatrane $\mathbf{P} @ \mathbf{2} \mathbf{d}$, probably because of the shielding of the aromatic linkers and the CTV cap.

\section{Catalytic Activity in confined Spaces}

As mentioned above, Verkade's superbases P@1 have played a significant role in the development of original nucleophilic and basic organocatalysts in various reactions. In order to investigate the effect of confinement on their catalytic activity, the encaged proazaphosphatrane $\mathbf{P} @ \mathbf{2} \mathbf{a}$ and its model parent $\mathbf{P} @ 3$ a were designed and synthesized by our group (Scheme 2 ). They were first tested in base-catalyzed Diels-Alder reactions of 3-hydroxy-2-pyrone with $\mathrm{N}$-methylmaleimide or dimethylfumarate (Scheme 4). ${ }^{[20]}$ Whereas the model proazaphosphatrane P@3 a gives high yields for both substrates, the catalytic activity of the encaged Verkade's superbase $\mathbf{P} @ \mathbf{2} \mathbf{a}$ is clearly substrate-dependent (Table 1). Indeed, when N-methylmaleimide is used as dienophile a quantitative yield is 
a)

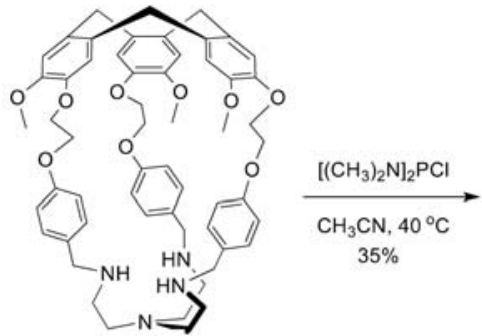

2a

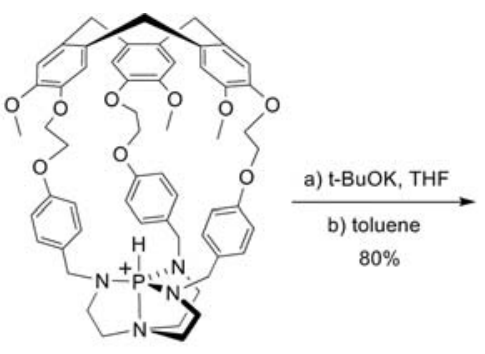

$\mathrm{PH}^{+} @ 2 \mathrm{a}$

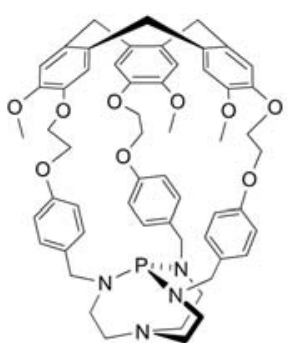

P@2a b)

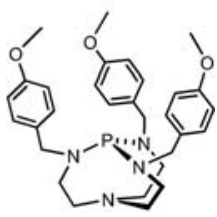

P@3a

Scheme 2. (a) Synthesis of the encaged Verkde's superbase $\mathbf{P} @ \mathbf{2} \mathbf{a}$ and (b) structure of its model counterpart P@3 a.
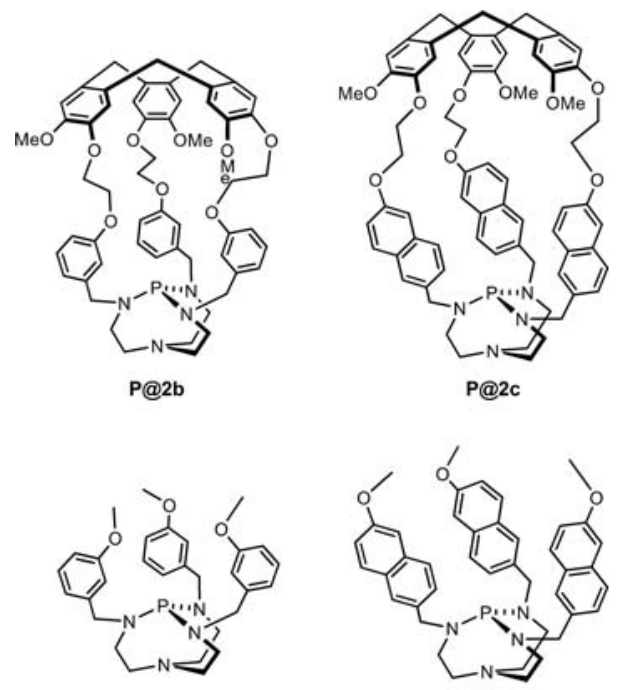

P@3b

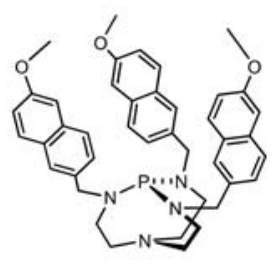

P@3c

Figure 1. Structures of encaged superbases $\mathbf{P} @ \mathbf{2} \mathbf{b}$ and $\mathbf{P} @ \mathbf{2} \mathbf{c}$ and of their model counterparts P@3 b and P@3 c.

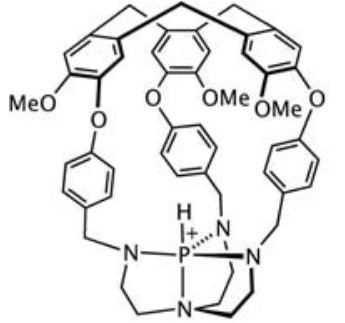

P-H+@2d

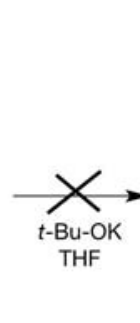

THF

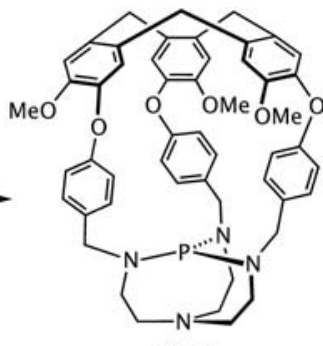

$\mathbf{P} @ 2 d$

Scheme 3. Structure of $\mathrm{PH}^{+} @ \mathbf{2} \mathbf{d}$ and attempted deprotonation to give P@2d.

reached, while no Diels-Alder product can be detected with trans-dimethylfumarate, probably because the pocket above the reactive phosphorus center cannot easily accommodate this more bulky substrate. If quantitative yields were achieved with both catalysts for the reaction between $\mathrm{N}$-methylmaleimide and 3-hydroxy-2-pyrone, an improvement of the diastereomeric excess was observed with the confined catalyst P@2 a (77\% and $43 \%$, respectively, both in favor of the 4-endo product, Table 1). The confinement of both substrates in a single cavity can limit the possible transition-state geometries, promoting the more

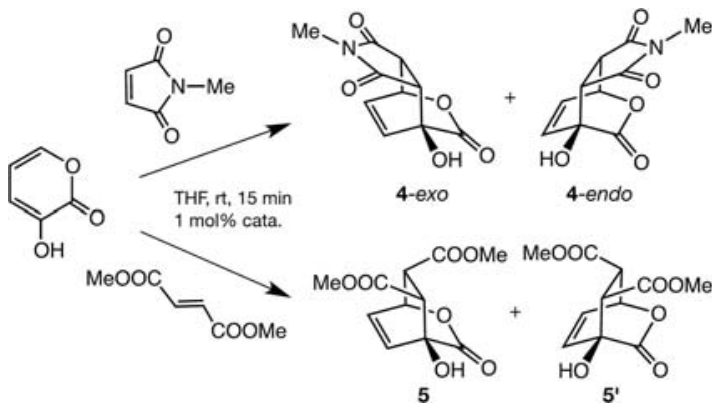

Scheme 4. Diels-Alder reactions of 3-hydroxy-2-pyrone with N-methylmaleimide or dimethylfumarate.

Table 1. Diels-Alder reaction between 3-hydroxy-2-pyrone and diethylfumarate or $\mathrm{N}$-methylmaleimide.

\begin{tabular}{|c|c|c|c|}
\hline dienophile & catalyst & Product $[\%]^{[\mathrm{a}]}$ & $d e[\%]^{[b]}$ \\
\hline dimethylfumarate & $\mathbf{P} @ 2 a$ & $5(<1)$ & - \\
\hline dimethylfumarate & $\mathbf{P} @ 3 a$ & $5(95)$ & 20 \\
\hline $\mathrm{N}$-methylmaleimide & $\mathbf{P} @ 2 \mathrm{a}$ & $4(100)$ & $77^{[c]}$ \\
\hline $\mathrm{N}$-methylmaleimide & $\mathbf{P} @ 3 a$ & $4(99)$ & $43^{[c]}$ \\
\hline
\end{tabular}

[a] Yield determined by NMR. [b] de determined by NMR. [c] The endo product is the major one.

compact ones and can account for the better selectivity of the encaged catalyst.

Then, the encaged Verkade's superbase P@2a was combined with a Lewis acid, titanium (IV) chloride, in order to create a Frustrated Lewis Pair (FLP) system. ${ }^{[21]}$ It was demonstrated that the acid-base reaction between these two partners was prevented by the confinement of the proazaphosphatrane in a cage structure. Indeed, when the model P@3a is mixed with $\mathrm{TiCl}_{4}$ the chlorinated azaphosphatrane $\mathrm{PCl}^{+} @ 3 \mathrm{a}$ is formed while this process does not occur when the confined superbase is used as Lewis base (Scheme 5 (b)). The lack of interactions between the confined superbase and the Lewis acid was supported by mass spectrometry and ${ }^{31} \mathrm{P}$ NMR experiments. Then, this FLP system was tested as catalyst in Morita-BaylisHillman (MBH) reactions (Scheme $5(\mathrm{a})$ ). The model superbases P@1, even with bulky R groups (i-propyl or p-methoxybenzyl), display almost no catalytic activity when combined with $\mathrm{TiCl}_{4}$. In sharp contrast, the confinement of the proazaphosphatrane turns its catalytic activity on, leading to a truly active FLP capable of increasing strongly the rate of $\mathrm{MBH}$ reactions. 
(a)

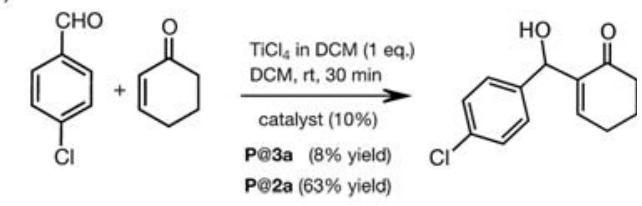

(b)

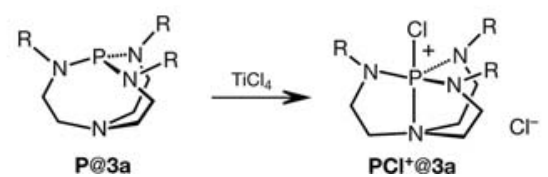

Scheme 5. (a) Example of a Morita-Baylis-Hillman (MBH) reaction catalyzed by model P@3 a and encaged superbase P@2 a. (b) Structure of the chlorinated azaphosphatrane $\mathrm{PCl}^{+} @ 3$ a resulting from the reaction of $\mathbf{P} @ 3$ a with $\mathrm{TiCl}_{4}(\mathrm{R}=\mathrm{p}$-methoxybenzyl).

Substrate selection and Inhibition experiments, as well as DFT calculations were performed and evidenced that the reaction occurs in the cavity of the hemicryptophane cage.

\section{Recognition of chiral azides}

Taking advantage of the convenient synthesis of the enantiopure hemicryptophanes $M-2 \mathrm{a}$ and $P-2 \mathrm{a}^{[22]}$ the enantiopure encaged azaphosphatranes $M-\mathrm{PH}^{+} @ \mathbf{2} \mathrm{a}$ and $P-\mathrm{PH}^{+} @ 2 \mathrm{a}$ and the corresponding encaged Verkade's superbases $M-P @ 2 \mathrm{a}$ and $P$ $\mathbf{P} @ 2$ a have been obtained following a pathway similar to that used for the racemic ligand $2 \mathrm{a}$ (Scheme 2a). Their absolute configurations (-)-M-P@2 a and (+)-P-P@2 a were assigned from electronic circular dichroism (ECD) spectra. Interestingly, the confined proazaphosphatranes were used as chiral derivatizing agents for chiral azides. Thus, the reactions between the enantiopure $M-\mathbf{P} @ 2$ a hemicryptophane and the racemic azides 6 or 7, led to the encaged diastereomeric phosphazide complexes 8 and 9 , respectively (Scheme 6). ${ }^{[23]}$ Although the chiral CTV moiety is remote form the phosphazide function, the $\left\{{ }^{1} \mathrm{H}\right\}^{31} \mathrm{P}$ NMR spectra of the resulting diasteromeric mixtures each display two well-defined signals, providing an easy access to the diastereomeric excess and highlighting the role of these enantiopure encapsulated proazaphosphatranes as chiral derivatizing agents for chiral azides.

\section{Azaphosphatranes in Confined Spaces}

\section{Catalytic activity in the confined space of molecular cavities}

The increase of the concentration of greenhouse gases in our environment is today a major world issue for its consequences on climate change and more importantly on human health and environmental concerns. The reduction of $\mathrm{CO}_{2}$ emissions is one solution that was considered by chemical approaches including its capture or conversion into useful chemicals.

Among the different approaches proposed, catalytic transformations are quite promising. Because of the high thermodynamic stability of $\mathrm{CO}_{2}$, metal-based catalysts have proved to be
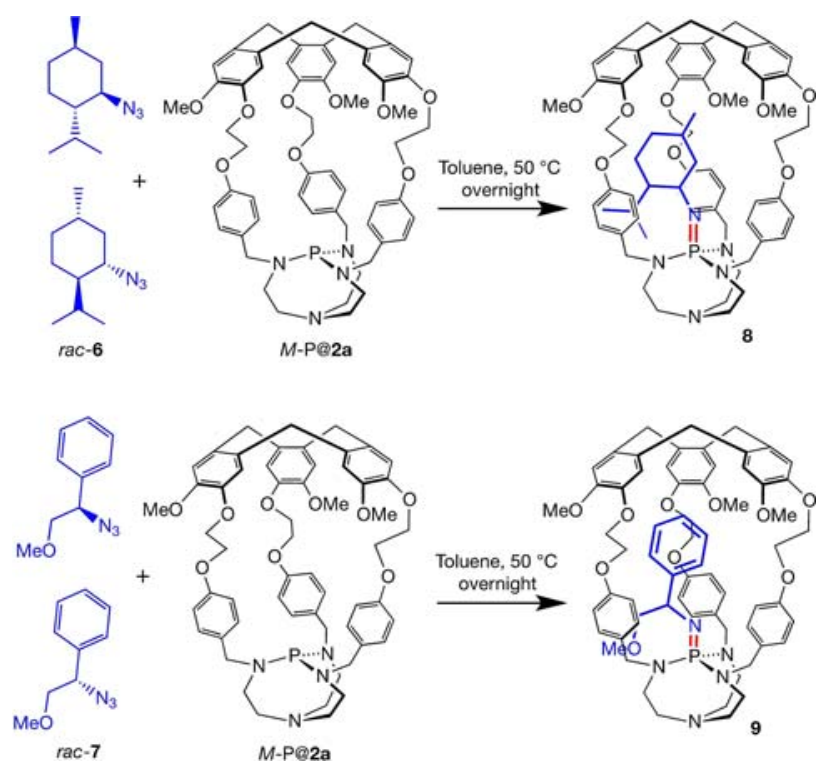

Scheme 6. Reaction between enantiopure encaged superbase $M-\mathbf{P} @ \mathbf{2}$ a with racemic azides 6 or 7 .

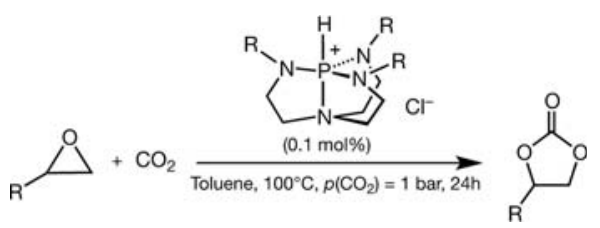

Scheme 7. Conversion of carbon dioxide into cyclic carbonates catalyzed by azaphosphatranes.

efficient in $\mathrm{CO}_{2}$ conversion. In the frame of this review, we should mention, among others, the synthesis of cyclic carbonates from $\mathrm{CO}_{2}$ using azaphosphatranes as efficient organocatalysts.

We have demonstrated that azaphosphatranes can be used as efficient organocatalysts for $\mathrm{CO}_{2}$ conversion (Scheme 7). ${ }^{[12]}$

Then, the effect of the confinement on the catalytic activity and stability of azaphosphatranes was investigated. ${ }^{[2]}$ The catalytic properties of $\mathbf{P H}^{+} @ \mathbf{2} \mathrm{a}, \mathbf{P H}^{+} @ \mathbf{2} \mathrm{b}, \mathbf{P H}^{+} @ \mathbf{2 c}$ were compared with those of their model parents $\mathrm{PH}^{+} @ 3 \mathrm{a}, \mathrm{PH}^{+}$ $@ 3 \mathrm{~b}, \mathrm{PH}^{+} @ 3 \mathrm{c}$ (Figure 2). The confinement was found to improve both the catalytic activity and the stability of azaphosphatranes. In particular, the catalytic activity of cage $\mathrm{PH}^{+} @ 2$ a remains constant with time whereas that of its model counterpart $\mathbf{P H}^{+} @ 3$ a clearly decreases over the same period (Figure 3). Thus, the cage protects the azaphosphatrane unit from degradation allowing a better stability of this organocatalyst. Whereas encapsulated azaphosphatranes $\mathrm{PH}^{+} @ \mathbf{2} \mathbf{a}$ and $\mathrm{PH}^{+} @ \mathbf{2} \mathbf{b}$, that exhibit a large cavity, display higher catalytic activities than their model counterpart $\mathrm{PH}^{+} @ 3 \mathbf{a}$ and $\mathrm{PH}^{+} @ 3 \mathbf{b}$, the encaged catalyst $\mathrm{PH}^{+} @ \mathbf{2} \mathrm{c}$ presenting a narrower cavity, leads to a much lower reactivity than its model parents $\mathbf{P H}^{+}$ $@ 3 c$. These results highlight how the shape and size of the nanospace above the reactive center can affect the catalytic 


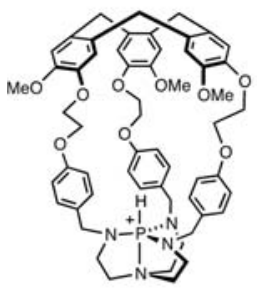

$\mathrm{PH}^{+} @ 2 \mathrm{a}$

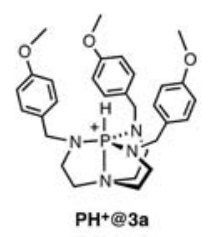

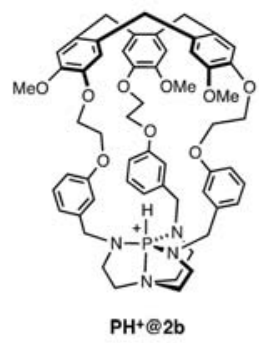
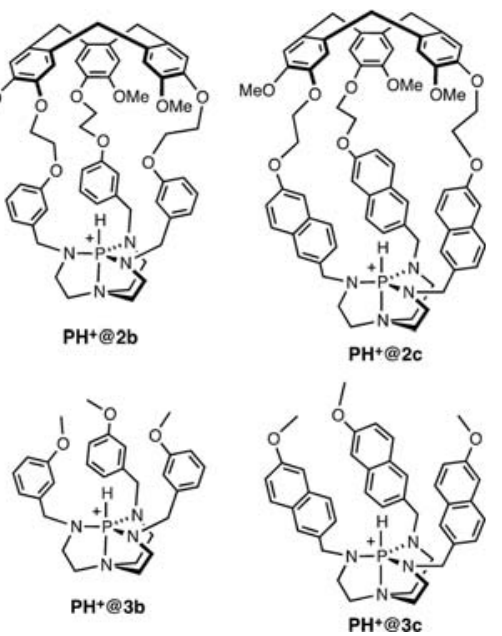

Figure 2. Structures of the confined and model azaphosphatranes used for the direct conversion of $\mathrm{CO}_{2}$. In each case the counterion is $\mathrm{Cl}^{-}$.

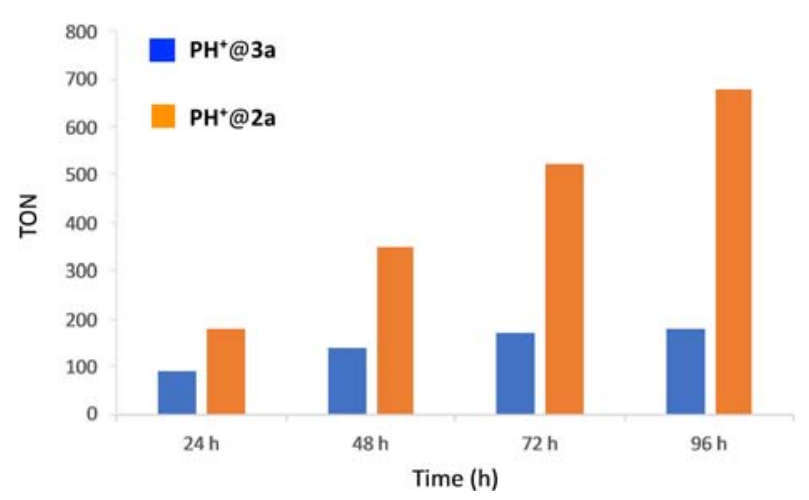

Figure 3. Cumulative TON for catalysts $\mathbf{P H}^{+} @ \mathbf{2} \mathrm{a}$ and $\mathrm{PH}^{+} @ 3 \mathrm{a}$. Reaction conditions: $\mathrm{CO}_{2}(1 \mathrm{bar})$, catalyst $(0.05 \mathrm{mmol})$, styrene oxide $(50.0 \mathrm{mmol})$, $\mathrm{T}=100^{\circ} \mathrm{C}$.

properties of the confined azaphosphatranes when used as catalysts for the conversion of $\mathrm{CO}_{2}$ to cyclic carbonates.

\section{Azaphophatranes in nanopores of mesoporous silica}

Another promising approach to azaphosphatrane catalysts in confined space has been developed through the design of heterogeneous polymeric or solid systems often recognized to reduce wastes and to facilitate recovery and reusability of the catalysts. This has been first proposed by J. G. Verkade who immobilized azaphosphatranes onto Merrifield resins giving rise to the efficient heterogeneous procatalysts $\mathrm{PH}^{+} @$ polym in dehydrohalogenations and debrominations of alkyl halides in the presence of $\mathrm{NaH}$, where the catalyst is the deprotonated form P@polym generated in situ (Scheme 8). ${ }^{[25]}$ The supported and model catalysts exhibit similar efficiency, although the polymeric form reacts more slowly but favor the recovery of the procatalyst. The analogous solid nitrate catalyst was later applied in Michael and Strecker reactions. The bound catalysts exhibited excellent catalytic activity and convenient recyclabil-
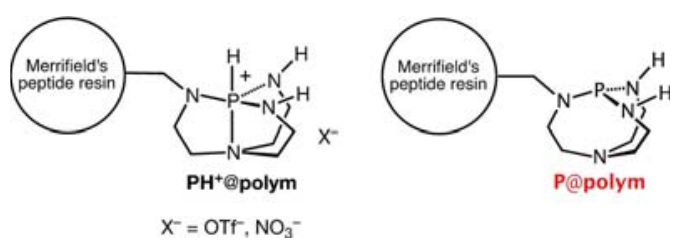

Scheme 8. Polymer supported azaphosphatrane procatalysts and their deprotonated forms.

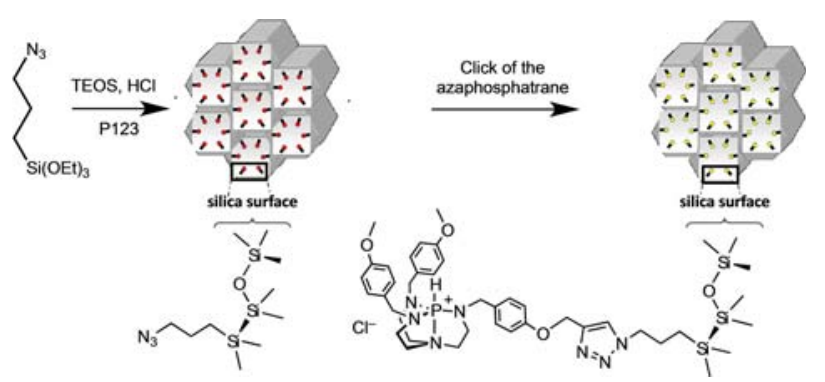

Scheme 9. Synthesis of the azaphosphatranes hybrid material.

ity. In the present case, mechanistic studies showed that the nitrate ion is the catalytically active species. ${ }^{[10]}$

Although these new catalysts immobilized on solid supports are not really representative of azaphosphatranes in confined space, an extension of this approach has been proposed by Martinez and Dufaud who grafted azaphosphatrane moieties in the nanopores of SBA-15 silica. These hybrid materials are a new kind of catalysts in confined space that were used for the synthesis of cyclic carbonates from epoxides and $\mathrm{CO}_{2}$. Their approach allows the preparation of diversely substituted azaphosphatranes. The organic inorganic hybrid materials were synthesized by click chemistry between adequately alkyne substituted precursors and SBA-15 mesoporous silica bearing azidopropyl groups, according to Scheme 9. ${ }^{[26]}$ Nevertheless, when compared to their model analogue, a decrease in the catalytic activity is observed. Diffusion constraints, induced by the location of the azaphosphatranes in the pores of the SBA-15 support, can account for this lower reactivity.

\section{Confined azaphophatranes for molecular recognition}

Azaphosphatranes have been introduced into polyhedral complexes by the means of the subcomponent self-assembly approach. ${ }^{[27]}$ This self-assembly was templated by anions in water, leading to a $\mathrm{Fe}(\mathrm{II})_{4} \mathrm{~L}_{4}$ tetrahedron endohedrally functionalized by azaphophatranes (Scheme 10). This cage is able to complex anions with volume ranging from 35 to $219 \AA^{3}$ by electrostatic interactions and hydrogen bonding, demonstrating, for the first time, that azaphosphatranes can be used as anion binding units. Depending on the size and shape of the anion, this water-soluble cage can adopt either a $C_{3}$ or $T$ symmetry, adapting dynamically its conformation to the template anion. The $T$-symmetric isomer displays a conformation where the four $\mathrm{P}-\mathrm{H}^{+}$bonds point inward the cavity, while 


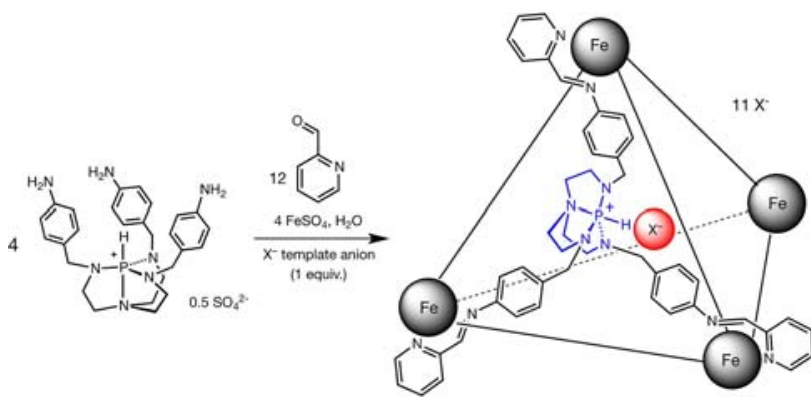

Scheme 10. Synthesis of the self-assembled cage in water, templated by the $\mathrm{X}^{-}$anion. $\mathrm{X}^{-}$can be $\mathrm{PF}_{6}^{-}, \mathrm{ReO}_{4}^{-}, \mathrm{TfO}^{-}, \mathrm{ClO}_{4}^{-}, \mathrm{CB}_{11} \mathrm{H}_{12}{ }^{-}, \mathrm{Tf}_{2} \mathrm{~N}^{-}, \mathrm{BF}_{4}^{-}, \mathrm{I}^{-}$or $\mathrm{NO}_{3}^{-}$.

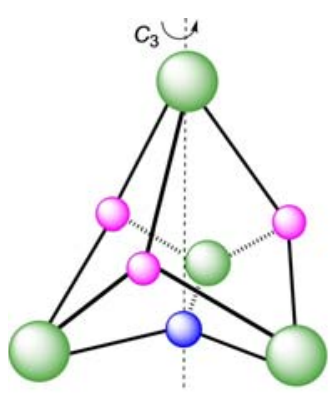

$C_{3}$-symmetric cage

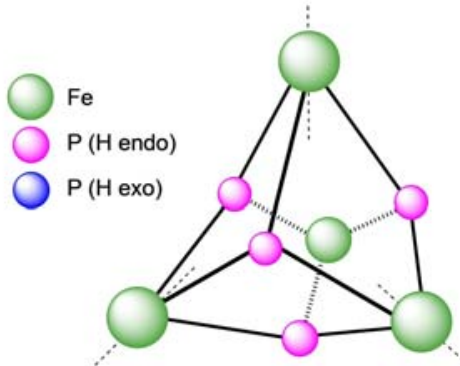

$T$-symmetric cage
Figure 4. Schematic representation of $C_{3}$-symmetric and $T$-symmetric cages. $C_{3}$ symmetry axes are drawn as dotted lines (right: only 3 of them are shown).

only three point inward and one outward for the $C_{3}$-symmetric arrangement (Figure 4). As the kinetic of interconversion of these two cage conformations is slow compared to that of guest displacement, a shape memory effect was observed: a first rapid guest displacement occurs while the $T / C_{3}$ ratio of the two conformations remains constant, followed by a slow reconfiguration templated by the new encaged anion. Although the cage lacking a template anion is not stable, the relative binding affinities were determined by competitive guest exchange, providing the following ranking for anion binding in water: $\mathrm{PF}_{6}^{-}>\mathrm{ReO}_{4}^{-}>\mathrm{TfO}^{-}>\mathrm{ClO}_{4}^{-}>\mathrm{CB}_{11} \mathrm{H}_{12}^{-}>\mathrm{Tf}_{2} \mathrm{~N}^{-}>\mathrm{BF}_{4}^{-}>$ $\mathrm{I}^{-}>\mathrm{NO}_{3}^{-}$.

Then, this $\mathrm{Fe}(\mathrm{II})_{4} \mathrm{~L}_{4}$ coordination cage was used for the biphasic selective extraction of anions. ${ }^{[28]}$ Tetrakis(3,5-bis (trifluoromethyl)-phenyl)borate $\left(\mathrm{BArF}^{-}\right)$was employed as counter-anion and $n-\mathrm{BuBF}_{3}{ }^{-}$as template anion giving the selfassembled cage $n-\mathrm{BuBF}_{3}{ }^{-}$. Perrhenate oxide $\mathrm{ReO}_{4}{ }^{-}$is a nonradioactive surrogate of pertechnetate $\left({ }^{99} \mathrm{TCO}_{4}{ }^{-}\right)$, which is a radioactive anion whose removal from nuclear waste is a key issue. It was found that $\mathrm{ReO}_{4}{ }^{-}$is fully extracted from water into nitromethane phase by this self-assembled cage. The extraction process is highly selective since, even in the presence of 10 competitive anions, $97 \%$ efficiency for $\mathrm{ReO}_{4}{ }^{-}$was reached. As the stability of this cage strongly depends on the solvent, the initial cage can be easily regenerated: the cage disassembles by switching from nitromethane to ethyl acetate, allowing the release of the guest in water, the self-assembled cage can then be restored by removing ethyl acetate and adding acetonitrile solvent and $n-\mathrm{BuBF}_{3}{ }^{-}$as template. This study opens a new way for the use of self-assembled cage for purification and uptake of pollutants from water.

\section{Conclusion}

In this Minireview, we have described the effect of the confinement on the properties of aza- ad pro-azaphosphatranes. These compounds have been encapsulated in covalent or selfassembled cages, leading to host molecules with endohedral functionalization. The confinement was found to affect the acid-base properties, the catalytic activity and selectivity, and the recognitions abilities of these compounds. This opens new routes for the development of unexplored applications of Verkade's superbases and their conjugated acids.

[1] a) C. Lensink, S. K. Xi, L. M. Daniels, J. G. Verkade, J. Am. Chem. Soc. 1989, 111, 3478-3479; b) M. A. H. Laramay, J. G. Verkade, J. Am. Chem. Soc. $1990,112,9421-9422$

[2] P. B. Kisanga, J. G. Verkade, R. Schwesinger, J. Org. Chem. 2000, 65, 5431-5432.

[3] For a review see: J. G. Verkade, P. B. Kisanga, Tetrahedron. 2003, 40, 7819-7858.

[4] For more recent examples: a) K. Wadhwa, J. G. Verkade, J. Org. Chem. 2009, 74, 4368-4371; b) S. M. Raders, J. G. Verkade, J. Org. Chem. 2010, 75, 5308-5311; c) J. Yang, B. Chatelet, F. Ziarelli, V. Dufaud, D. Hérault, A Martinez, Eur. J. Org. Chem. 2018, 45, 6328-6332.

[5] a) J. V. Kingston, J. G. Verkade J. Org. Chem. 2007, 72, 2816-2822; b) S. Urgaonkar, J. H. Xu, J. G. Verkade, J. Org. Chem. 2003, 68, 8416-8423.

[6] a) Z. Thammavongsy, J. F. Khosrowabadi Kotyk, C. Tsay, J. Y. Yang, Inorg. Chem. 2015, 54, 11505-11510; b) Z. Thammavongsy, M. K. Ivy, J.W. Ziller, J.Y. Yang, Dalton Trans. 2016, 45, 9853-9859; c) Z. Thammavongsy, D. W. Cunningham, N. Sutthirat, R. J. Eisenhart, J. W. Ziller, J. Y. Yang, Dalton Trans. 2018, 47, 14101-14110; N. Sutthirat, J. W. Ziller, J. Y. Yang, Z. Thammavongsy, Acta Crystallogr. 2019, E75, 438-442.

[7] B. Chatelet, P. Nava, H. Clavier, A. Martinez, Eur. J. Inorg. Chem. 2017, 37, 4311-4316.

[8] a) S. Mummadi, D. K. Unruh, J. Zhao, S. Li, C. Krempner, J. Am. Chem. Soc. 2016, 138, 3286-3289; b) S. Mummadi, D. Kenefake, R. Diaz, D. K. Unruh, C. Krempner, Inorg. Chem. 2017, 56, 10748-10759.

[9] a) T. C. Johnstone, G. N. Wee, D. W. Stephan, Angew. Chem. Int. Ed. 2018, 57, 5881-5884; Angew. Chem. 2018, 130, 5983-5986; b) T. C. Johnstone, A. I. Briceno-Strocchia, D. W. Stephan, Inorg. Chem. 2018, 57, 1529915304.

[10] B. M. Fetterly, N. K. Jana, J. G. Verkade, Tetrahedron 2006, 62, 440-456.

[11] P. Dimitrov-Raytchev, J.-P. Dutasta, A. Martinez, ChemCatChem 2012, 4, 2045-2049.

[12] a) B. Chatelet, L. Joucla, J.-P. Dutasta, A. Martinez, K. C. Szeto, V. Dufaud, J. Am. Chem. Soc. 2013, 135, 5348-5351; b) B. Chatelet, E. Jeanneau, J.-P. Dutasta, V. Robert, A. Martinez, V. Dufaud, Catal. Commun. 2014, 52, 2630.

[13] D. Zhang, A. Martinez, J.-P. Dutasta, Chem. Rev. 2017, 117, 4900.

[14] C. Colomban, B. Châtelet, A. Martinez Synthesis 2019, 51, 2081-2099.

[15] a) M. Delecluse, C. Colomban, D. Moraleda, I. de Riggi, F. Duprat, S. Michaud-Chevallier, J.-P. Dutasta, V. Robert, B. Chatelet, A. Martinez, Chem. Eur. J. 2019, 25, 3337; b) J Yang, B. Chatelet, V. Dufaud, D. Hérault, 
M. Jean, N. Vanthuyne, J.-C. Mulatier, D. Pitrat, L. Guy, J.-P. Dutasta, A Martinez, Org. Lett. 2020, 22, 891-895; c) A. Long, O. Perraud, M. Albalat V. Robert, J.-P. Dutasta, A. Martinez, J. Org. Chem. 2018, 83, 6301-6306.

[16] a) S. A. Ikbal, C. Colomban, D. Zhang, M. Delecluse, T. Brotin, V. Dufaud, J.-P. Dutasta, A. B. Sorokin, A. Martinez, Inorg. Chem. 2019, 58, 72207228; b) D. Zhang, K. Jamieson, L. Guy, G. Gao, J.-P. Dutasta, A. Martinez, Chem. Sci. 2017, 8, 789-794.

[17] P. D. Raytchev, A. Martinez, H. Gornitzka, J.-P. Dutasta, J. Am. Chem. Soc. 2011, 133, 2157-2159.

[18] B. Chatelet, H. Gornitzka, V. Dufaud, E. Jeanneau, J.-P. Dutasta, A. Martinez, J. Am. Chem. Soc. 2013, 135, 18659-18664.

[19] Y. Makita, K. Furuyoshi, K. Ikeda, T. Fujita, S.-I. Fujiwara, M. Ehara, A. Ogawa, Tetrahedron Lett. 2011, 52, 4129-4131.

[20] B. Chatelet, V. Dufaud, J.-P. Dutasta, A. Martinez, J. Org. Chem. 2014, 79, 8684-8688.

[21] J. Yang, B. Chatelet, V. Dufaud, D. Hérault, S. Michaud-Chevallier, V. Robert, J.-P. Dutasta, A. Martinez, Angew. Chem. 2018, 130, 1440814411; Angew. Chem. Int. Ed. 2018, 57, 14212-14215.

[22] S. Lefevre, D. Zhang, E. Godart, M. Jean, N. Vanthuyne, J.-C. Mulatier, J.P. Dutasta, L. Guy, A. Martinez, Chem. Eur. J. 2016, 22, 2068-2074.
[23] J. Yang, B. Chatelet, D. Hérault, V. Dufaud, V. Robert, S. Grass, J. Lacour, N. Vanthuyne, M. Jean, M. Albalat, J.-P. Dutasta, A. Martinez, Chirality 2020, 32, 139-146.

[24] B. Chatelet, L. Joucla, J.-P. Dutasta, A. Martinez, V. Dufaud, Chem. Eur. J. 2014, 20, 8571-8574.

[25] X. Liu, J. G. Verkade, J. Org. Chem. 1999, 64, 4840-4843.

[26] B. Chatelet, L. Joucla, J.-P. Dutasta, A. Martinez, V. Dufaud, J. Mater. Chem. 2014, 2, 14164-14172.

[27] D. Zhang, T. K. Ronson, J. Mosquera, A. Martinez, L. Guy, J. R. Nitschke, J. Am. Chem. Soc. 2017, 139, 6574-6577.

[28] D. Zhang, T. K. Ronson, J. Mosquera, A. Martinez, J. R. Nitschke, Angew. Chem. Int. Ed. 2018, 57, 3717-3721; Angew. Chem. 2018, 130, 37793783. 